\title{
MAINTAINING THE TRANSPORT SYSTEM UNDER EXTREME WEATHER EVENTS: A DUAL-NETWORK PERSPECTIVE
}

\author{
Xin MIAO ${ }^{\mathrm{a}}$, David BANISTER ${ }^{\mathrm{b}}$, Yanhong TANGa ${ }^{\mathrm{a}}$, Min $\mathrm{LI}^{\mathrm{a}}$, Bao XI ${ }^{\mathrm{c}}$ \\ a School of Management, Harbin Institute of Technology, 150001 Harbin, P.R. China \\ ${ }^{\mathrm{b}}$ Transport Studies Unit, School of Geography and the Environment, University of Oxford, \\ OX1 3QY Oxford, United Kingdom \\ 'School of Public Administration, Dalian University of Technology, 116024 Dalian, China
}

Received 23 June 2012; accepted 16 June 2013

\begin{abstract}
Recent years have seen an increase in the frequency of extreme weather events globally, and these have resulted in severe impacts on the transport system. To the means by which the transport system can be maintained under extreme weather events is an emerging topic in transport studies, and this is augmented by a growing concern about climate change. This paper considers transport system as dual-network composed of an interrelated operation level and management level that has some similarities with the theory behind the Wardrop Principle. Evidence from the case study on the snow event in South China in early 2008 is used to draw the dual-network formulation to generalise the law of maintaining the transport system under extreme weather. The mathematical models of the dual-network focus on entropic dynamics in the operation network and matching control activities in the management network. Quantitative evidence is provided to prove the methodology. Interactions through the form of information communication and organisational collaboration within and between networks are highlighted. Incentive mechanisms are emphasised for achieving effective anticipation, prevention and collaboration to coping with extreme weather events. This paper contributes to a better understanding about the role of networks, collective behaviour, information interchange and inter-organisational collaboration in influencing the maintenance of transport system under extreme weather conditions.
\end{abstract}

Keywords: transport system, climate change, extreme weather, management, dual-network, mathematical model, case study, China.

Reference to this paper should be made of follows: Miao, X.; Banister, D.; Tang, Y. H.; Li, M.; Xi, B. 2013. Maintaining the transport system under extreme weather events: a dual-network perspective, Technological and Economic Development of Economy 19(Supplement 1): S342-S359.

JEL Classification: H12, L91, O18, P41, R41.

Corresponding author Xin Miao

E-mail:miaoxin@hit.edu.cn,xin.miao@aliyun.com 


\section{Introduction}

Climate change has increased the likelihood of extreme weather phenomena, and these events refer to severe or unseasonal weather that are rare and occur only $5 \%$ or less in the historical meteorological distribution (IPCC 2001; IPCC 2007; Zhu, Thot 2001). Such extreme weather events often lead to disasters. However, there is difference between an extreme weather event and a disaster. The concept of a disaster can be defined as "Severe alterations in the normal functioning of a community or society due to hazardous physical events interacting with vulnerable social conditions, leading to widespread adverse human, material, economic or environmental effects that require immediate emergency response to satisfy critical needs and that may require external support for recovery" (IPCC 2012). Many extreme events occur but they are only disasters when the community experiencing the event is not prepared to cope with it. Thus, preparation to cope with an extreme weather event is critical to prevent it evolving into a disaster. However, people are often not good at this. In the past year (2011), twelve extreme weather events occurred in the US, each costing more than $\$ 1$ billion (Peralta 2011). Extreme weather has become a sort of severe threat to sustainable development (Mirza 2003; Kovats et al. 2005).

The impacts of extreme weather on transport system may range from an increase in the discomfort to travellers to increase in the system vulnerability (Nagurney et al. 2010) and degradation of the transport system (Al-Deek, Emam 2006). The disturbances to the transport system may further cause substantial economic and social strains and threaten life and health (Jenelius 2009). The effects of extreme weather on transport system have been mainly mentioned in the context of network reliability and vulnerability but not in the specific context of extreme weather conditions (Sumalee et al. 2011). Suarez et al. (2005) have noticed that "transport sector in general is not considering adaptation as a solution to these potential impacts".

Unlike most previous work that focused on transport network reliability and vulnerability, this paper considers the transport system as a dual-network composed of the operation level and the management level. Besides the introduction, the paper includes three parts. Part I (section 1) provides fact and analysis about the snow event in early 2008 in South China relating to the operation level and management level. Part II (sections 2, 3, 4, 5) uses the fact and evidence presented in part I and explains the utility of the formulation that has been developed in Part II, and further confirms the methodology by quantitative evidence. Part III (sections 6 and 7) draws on evidence and analysis presented earlier.

\section{Case study about the transport system under the snow event in South China in early 2008}

\subsection{Disorder in the operation level}

Between January 10 and February 2, 2008, there were four episodes of severe and persistent snow, low-temperature and freezing weather in the Yangtze River basin, in the South China and South-West China regions (Shi et al. 2010). It had seldom snowed in South China, so the heavy snow surprised many people, and they had no experience of how to respond to this rare 
event. The snow closed highways, as well as stranding millions of passengers. As reported by Xinhua News Agency on $27^{\text {th }}$ January 2008, there were "more than 40,000 passengers in at least 5,000 broken-down vehicles on expressways between Guizhou province and neighbouring Guangxi Zhuang Autonomous Region; the delays of at least 136 trains in Hunan Province, a result of power failure, stranded almost 150,000 passengers at Guangzhou Railway Station on Saturday night" (Xinhua News Agency 2008) (Locations of provinces, autonomous regions and municipalities are shown as Fig. 1). By the end of January 2008, the number of stranded passengers in Guangzhou Railway Station has exceeded 100,000. However, the public were not told about the expected weather conditions in advance, and travel information was only limited in its relevance and quality. As a result, more passengers streamed into railway stations and they were trapped there. The slow response of local government caused public resentment and social unrest. As the complaints increased, emotions were raised, and there were disturbances in some stations. The state in these stations became difficult to control. China's premier Wen Jiabao had to visited several railway stations to placate the stranded passengers. This sequence of the event illustrates the causal chain effects resulting from the extreme weather, causing subsequent collective behaviour, and it resulted in the increased risk of disturbance. This event demonstrates the interconnectedness between the sectors and the important role that transport plays in maintaining social harmony.

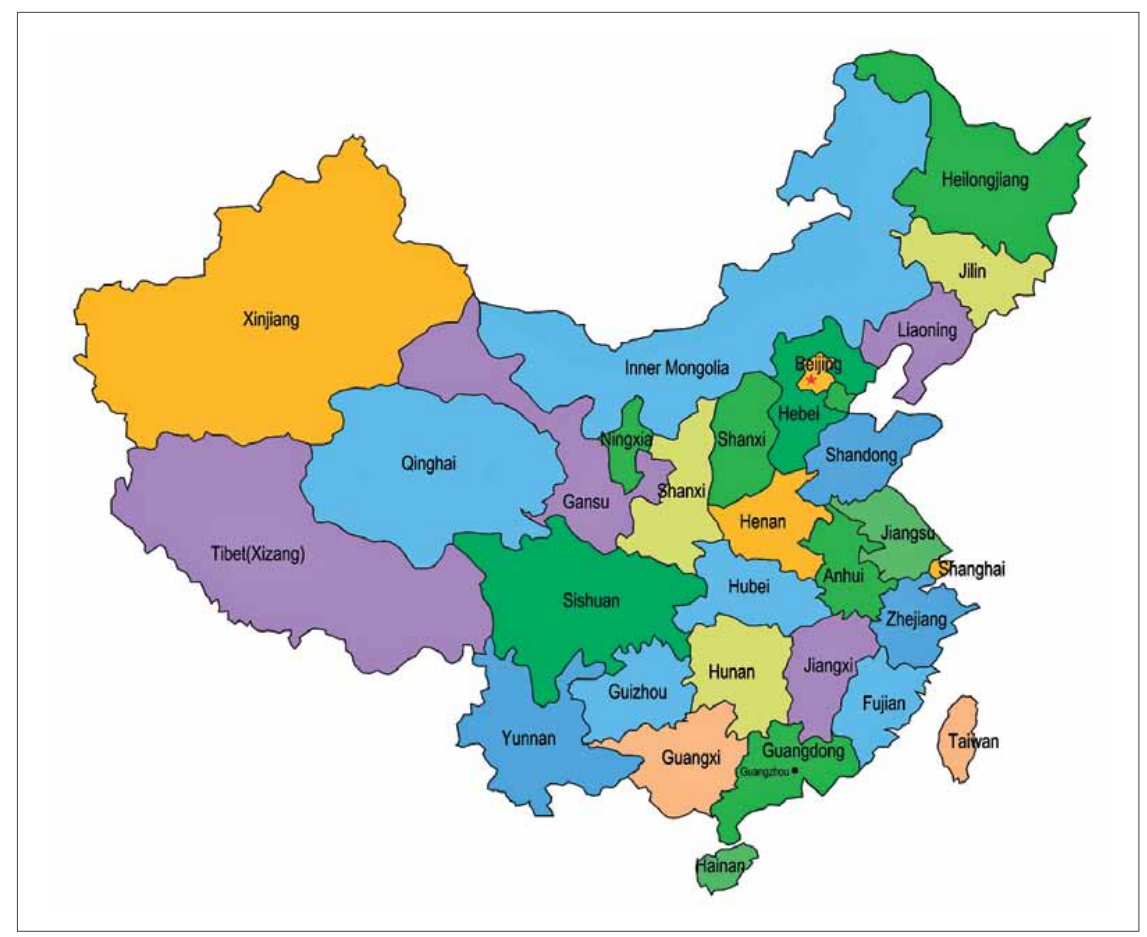

Fig 1. Map of China: locations of provinces, autonomous regions and municipalities 


\subsection{Defects in the management level}

There is an obvious neglect on planning based on climatological probabilities. Many officials in South China believe snow events always happen in the northern regions and so they do not need to consider that matter themselves. "Warm winter" gossip had become popular in recent years, as it seems that winter is really not cold any more. Therefore, there is a prominent oversight on dealing with the potential problem of snow defence.

Starting in 2004, the total pre-arranged emergency plans in China had amounted to 24,293 items as of March 15, 2006 (Shi et al. 2007), however, the vast number of pre-arranged emergency plans did not achieve desired results in the snow event response. The transport sector did not receive any relevant emergency training prior to the event and it did not establish effective advance emergency management systems.

The transport sector did not make special analysis, evaluation and judgement on the information from the weather forecasting sector. The land and the air transport sectors continued to sell tickets to passengers even when the heavy snow was already beginning to fall, and this resulted in passengers being stranded in stations. More frustrating was the fact that the central government had issued a warning notice to local officials, however, these individuals failed to forward this message to those in the subordinate areas, as a matter of urgency. Full use was not made of the early warning time to try to control danger, and this resulted in the "golden time" being lost.

Almost all the severely affected southern provinces demonstrated an acute shortage of snow clearing equipment. One typical example was that a highway in Jiangxi province possessed only one snow removal vehicle, and such a severe shortage of equipment led to traffic jams in this area that lasted for three days.

Besides, human capital in emergency response process has not been fully mobilised. Public participation can improve the efficiency in coping with extreme weather events, as this can involve the vast, extensive and quick response characteristics of civic society. If this potential can be fully activated, the ability of the transport sector to respond effectively would be considerably enhanced. Although China's emergency response planning clearly states the need to increase public participation, the real situation is far from satisfactory. There is an obvious gap between officials and citizens in terms of their ability to communicate and cooperate with each other. For example, some local governments have issued several notices to urge citizen to participate in the snow and ices cleaning, however, few people are actively involved in this process.

In facing large-scale extreme weather events, it is unwise for the transport sector to act alone. It is better to cooperate with other related sectors so that the full range of actions can be taken in the emergency response process. However, handicaps in the coordination and communication with other sectors were prominent in the snow event. For example, the railway sector wished to resume the rail operations as soon as possible, and they publicised information that trains would restart in a few days. However, the local government in the affected area wished to comfort the stranded passengers, and they released contrary information to instruct the passengers to stay at the station and to celebrate the Spring Festival. The conflicting information made the stranded passengers, who have already become restless and strained with rising concerns resulting from the prolonged stay at the station, become even more annoyed, and this resulted in civil disobedience. 


\subsection{Crisis digestion through matching control}

With the visiting of China's premier Wen Jiabao to several railway stations, temporary special office for transport coordination was constituted in each stricken province. These special offices communicated among each other and cooperated with the railway sector. Take the most severely affected Guangdong Province as an example, the special office in Guangdong Province informed the other special offices to suspend departure to Guangzhou (the provincial capital of Guangdong Province) direction for a period of time to ease the pressure of the Guangzhou station. Besides, in the late night of February 1, 2008, the Guangzhou government enabled the Pazhou International Convention and Exhibition Centre and other five primary and secondary schools as temporary places for stranded passengers and storing relief supplies. By the end of February 5, 2008, the crisis in Guangzhou railway station gradually lifted.

The railway authorities also took actions to support the local governments and managers to alleviate the crisis. The railway sector enabled the diesel locomotive for railway transport to restore the Beijing-Guangzhou railway running order. The Guangzhou Railway Group deployed 411 diesel locomotives to participate and the Ministry of Railways mobilised 146 diesel locomotives from the adjacent Nanning and Wuhan Railway Bureau to support the response. Besides, from January 28 to February 9, the Guangzhou Railway Group offered a total of 4,326 tons of diesel oil to support the diesel locomotive ferry. The railway sector also provided information about railway transport capacity several times daily to the special office for transport coordination and collaborated with local government in publishing of information via a variety of ways to guide travelers. Such corresponding matching control contributed to the gradual digestion of the crisis.

\section{Analysis of dual-network characteristics of transport system}

Transport system is a man-made complex system which has been constructed for people, vehicles, roads and other infrastructures. The human element has adaptability and it is the most active part of the system. Since the term "adaptation build complexity" (Holland 1995) has emerged from the literature, the transport system can be seen as a kind of Complex Adaptive System (CAS) (Hongler et al. 2010). This system may emerge through two kinds of networks, that is, the operation network and the management network. This interpretation has some similarities with the two levels implied in the Wardrop principle (Wardrop 1952) where traffic distribution optimization takes place at two levels, namely the user level and the system level (manager level).

This paper considers these two levels as a dual-network and it will focus on the network effects and the interrelations between networks. However, unlike the Wardrop theory, the dual-network has broader meanings. For the operation network, it covers all kinds of operating elements from infrastructures to vehicles and travellers. While at the management network, it covers the managers not only in transport sector but also in other related sectors. Transport emergency management under extreme weather events involves various information and resources from transport sector and other sectors. So the dual-network is more complex and 
involves more factors and actors than the two levels expressed in the Wardrop theory. The dual-network can be defined as follows:

Let $G_{o}=\left(O, E_{o}\right)$ denote the operation network. Where, $O=\left(o_{1}, o_{2}, \cdots, o_{n}\right)$ denotes the set of elements; $E_{o}=\left\{\left(o_{i}, o_{j}\right)\right\}, i, j=1,2, \cdots, n$, denotes the set of relations. Therefore, $\left(o_{i}, o_{j}\right)$ denotes the connections or some interactions between the elements $o_{i}$ and $o_{j}$.

Let $G_{m}=\left(M, E_{m}\right)$ denote the management network. Where: $M=\left\{m_{1}, m_{2}, \cdots, m_{l}\right\}$ denotes the set of managers; $E_{m}=\left\{\left(m_{i}, m_{j}\right)\right\}, i, j=1,2, \cdots, l$, denotes the set of relations. Therefore, $\left(m_{i}, m_{j}\right)$ denotes the interactions between manager $m_{i}$ and $m_{j}$.

The management network and the operation network are inter-embeded. The interactions between the two networks can be further formulated as follows:

The situation, one type of manager has influence on some operating elements, and this can be denoted as:

$$
O\left(m_{i}\right)=\left\{o_{j} \mid o_{j} \in O, \eta\left(m_{i}, o_{j}\right)=1\right\}
$$

where: $O\left(m_{i}\right)$ denotes the set of operating elements affected by one type of manager $m_{i}$; $\eta\left(m_{i}, o_{j}\right)=1$ denotes the influence that one type of manager $m_{i}$ has on the operating element $o_{j}, j=1,2, \cdots, n$. Therefore, $n$ denotes the number of operating elements.

The situation where one operating element is influenced by some managers can be denoted as:

$$
M\left(o_{i}\right)=\left\{m_{j} \mid m_{j} \in M, \lambda\left(o_{i}, m_{j}\right)=1\right\}
$$

where: $M\left(o_{i}\right)$ denotes the set of managers who have an influence on the operating element $o_{i} ; \lambda\left(o_{i}, m_{j}\right)=1$ denotes that $o_{i}$ is influenced by manager $m_{j}, j=1,2, \cdots, n$. Where $n$ denotes the number of managers.

The above formulas depict the static relations. As the networks are dynamic and interact with the help of information transmission, there is a "flow", which is an important concept in the CAS theory. Transport system can be seen as a system composed of the operationmanagement dual-network (Fig. 2).

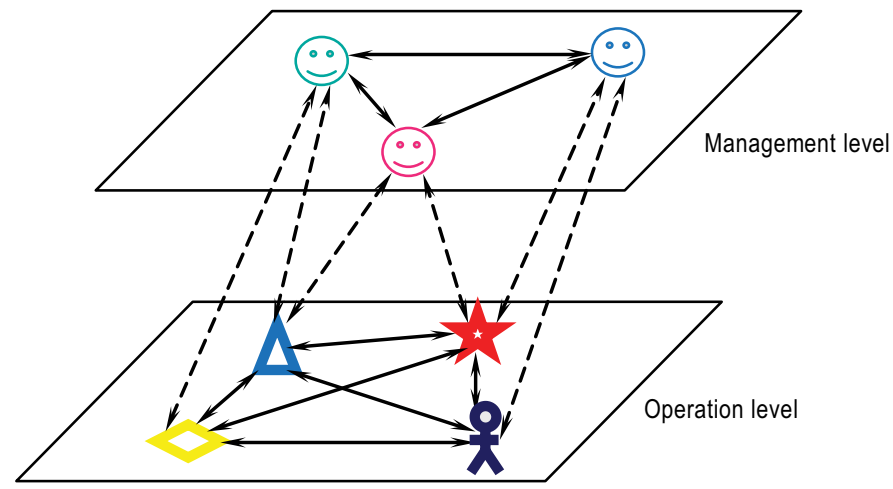

Fig 2. Abstracted dual-network structure 


\section{Formalising the way to high states of disorder in the operation network level}

A direct impression about the impact of extreme weather events on the transport system might be a major traffic accident and a paralysed traffic system. In fact, there are various ways that extreme weather events may impact on the transport system. Since the operation of transport is interdependent (Johansson, Hassel 2010) with other critical infrastructures, which may cover power grid, gas network, communication network and so on (Bosher et al. 2007). The interdependency of critical infrastructures (Eusgeld et al. 2011) might induce cascading failures (Santella et al. 2009; Zio, Sansavini 2011) during a disaster caused by an extreme weather event and result in a worse transport state beyond expectation.

We may foresee intuitively that disasters generated by extreme weather events usually hit physical components first and arouse cascading failures of critical infrastructures. If handled improperly, the impact will upgrade and shake social components, causing panic, unrest and crisis. Since the human is the most active element in transport system even in any socio-technical system, extreme weather events will affect the cognition and behaviour of involved people, inducing accidents, resulting in extensive panic, and this might push the involved people into a disorder state. The following cognitive and psychological analysis will explain the impact transition.

Irrational collective behaviour might arise in passenger groups when outside condition gets worse under extreme weather events, and passengers are left in a stage of information shortage. They are anxious about the current situation and the coming. Cognitive and psychological knowledge can help in analysing the panic emotion that contributes to the transition of disorder state from physical systems to social systems. The uncertainties of extreme weather may induce passengers' strain because passengers do not know about the likely duration of the event, the exact situation with respect to the event, whether the situation is controllable, and what might happen.

In this situation where there is a rare extreme weather event and an information shortage, the behaviour of a passenger is unavoidably influenced by others. Most individuals usually consider others' behaviour as being a conceivable choice to follow, rather than taking their own decision based on rational thinking. This phenomenon has universality, as social psychology studies have shown that such behaviour will become public information sources when the objective reality is blurred (Quarantelli 1957; Kelley et al. 1965). Individuals often consider mass action as being valid, as other information and viable options are absent during the emergency situation. The most influential research to support this view is a set of articles published in Nature (Low 2000; Helbing et al. 2000). Helbing et al. (2000) summarised some common characteristics about collective behaviour under emergency conditions.

The cascading dynamics of collective behaviour can be modelled by consulting herd behaviour theory (Lux 1995). A passenger, who obtains segmental information, tends to follow others' behaviours under emerging circumstances. The dynamics can be analysed by mathematical models (Miao et al. 2011):

Let $2 \mathrm{~N}$ denote the sum of passengers. Let $n_{-}$denote the sum of panicky passengers who are likely to follow irrational behaviour and $n_{+}$denote the sum of calm passengers who are unlikely to act in an abrupt manner. $n_{+}+n_{-}=2 N$. Let $n=0.5\left(n_{+}-n_{-}\right)$and $x=n / N, x \in[-1,1]$. 
When $x$ is nil, there is an equivalent number of panicky passengers and calm passengers. When $x<0$, it means that the panicky passengers are in the majority. When $x>0$, it means that the calm passengers are in the majority. When $x=-1$, there are no calm passengers. When $x=1$, there are no panicky passengers.

The transformation probability of calm passengers to panicky passengers can be denoted as $P_{+-}$. In the same way, the transformation probability of panicky passengers to calm passengers can be denoted as $P_{-+} . P_{+-}$and $P_{-+}$are determined by the distribution of $x$ or $n$ :

$$
\begin{aligned}
& P_{+-}=P_{+-}(x)=P_{+-}(n / N) ; \\
& P_{-+}=P_{-+}(x)=P_{-+}(n / N) .
\end{aligned}
$$

Equations (1) and (2) reflect the assumption that the emotion or attitude of one passenger will be influenced by others. To simplify this problem, suppose the perception of a passenger will alter just once, that is, a panicky passenger may become calm and vice versa. Then, assume the conversion probability is the same for any passenger. Therefore, let $P_{+-} n_{-}$denote the number of passengers transferred from panicky to calm, and $P_{-+} n_{+}$denote the number of passengers transferred from calm to panicky.

The transformation ratios can be formulated as per the formulations demonstrated by Miao et al. (2011). Therefore, the dynamics of the collective behaviour can be depicted as:

$$
\begin{aligned}
& \frac{d x}{d t}=(1-x) v e^{a x}-(1+x) v e^{-a x}= \\
& 2 v[\sinh (a x)-x \cosh (a x)]=2 v \cosh (a x)[\tanh (a x)-x] .
\end{aligned}
$$

Information cascade (Banerjee 1992; Bikhchandani et al. 1992) is an important concept in supporting the study on dynamics of the collective behaviour. "An informational cascade occurs when it is optimal for an individual, having observed the actions of those ahead of him, to follow the behaviour of the preceding individual, without considering his own information" (Bikhchandani et al. 1992). This argument can explain the forming of collective behaviour.

By referring to the basic ideas from Bikhchandani et al. (1992), the influence of emergent collective behaviour under extreme weather is analysed. Suppose every passenger has two kinds of behaviour, either rational or irrational, denoted respectively as $A$ and $B$, assume that each has a probability of 0.5 . Let $L$ and $H$ denote the private information (Hey, Morone 2004). When $V=A$, it is more possible that individual has owned the information $H$; when $V=B$, it is more possible that individual has owned the information $L$. That is:

$$
\begin{gathered}
P(X=H \mid V=A)=p ; \\
P(X=H \mid V=B)=1-p,
\end{gathered}
$$

where: $0.5<p<1$.

Similarly:

$$
\begin{gathered}
P(X=L \mid V=B)=p ; \\
P(X=L \mid V=A)=1-p .
\end{gathered}
$$


In addition to private information, every passenger tends to observe what others do and considers the observed as reference before his decision-making.

The first passenger takes action according to his own private information. Because of Bayesian formula, if he owns private information $L$, he is more likely to exhibit behaviour $B$. That is:

$$
P(V=B \mid L)=\frac{P(L \mid V=B) \times P(V=B)}{P(L \mid V=B) \times P(V=B)+P(L \mid V=A) \times P(V=A)}=\frac{p \times 0.5}{p \times 0.5+(1-p)}>0.5 .
$$

The second passenger takes action based on his own private information and the behaviour of the first passenger. If his private information is $L$ and he sees the first passenger has exhibited behaviour $B$, he will naturally exhibit behaviour $B$, too. If $H$ is his private information, he has to make decision based on contradictory information, then he will choose $A$ or $B$ by chance or seek other information for reference.

The third passenger takes action according to composite consideration of his own private information and the behaviour of the previous two passengers. If he sees both of them have chosen $B$, he will be convinced that the previous two passengers possess private information $L$. According to Bayesian formula, even if the third passenger has owned private information $H$, he will still tend to exhibit behaviour $B$. This is due to $P(V=A>0.5)$ and information cascade of the $B$ will form. The occurrence probability of information cascade can be mathematically deduced as $\left(1-p+p^{2}\right)$. Therefore, if $\left|N_{A}-N_{B}\right| \geq 2$, an information cascade may emerge and this will lead to collective behaviour.

Extreme weather conditions may generate disasters, which likely pose life-threatening situations and trigger stampedes of group people (Keating 1982), so passengers tend to feel strained and apperceive sensitive information, and this situation will increase the possibility of panicky collective behaviour without clear cause (Helbing et al. 2000). Therefore, on one hand, extreme weather will debase the connectivity and capacity of transport system; on the other hand, the collective behaviour triggered by panicky emotion and information shortage will easily lead to people's turbulence, which will in turn make the transport condition even worse. It is necessary to control collective behaviour to avoid greater losses. It is vital that public information is provided in a timely manner, and is of such a nature as to lead to behaviours that optimise societal outcomes. Once the proper information is understood by passengers, the improper collective behaviour will get mitigation. The formulation developed in this section is supported by and accounts for the facts about the formation and dissipation of the collective behaviour in the snow event in South China in early 2008.

\section{Modeling the matching control from the management network level}

Under the risks of extreme weather events, the transport management department should send early warning information about the coming extreme weather, make quick response to accidents as they occur, and release relevant information to travellers that promotes calm, rational decision making that doesn't endanger others. Effective assessment on the situation and swift response to accidents are critical in reducing the secondary effects and losses in the face of uncertainties under extreme weather. Information collection is a necessary 
precondition for assessment and decision making. It is important to possess the following information: (1) Basic information, including time, location, road type, weather conditions and traffic flow information, etc.; (2) Event information, including the damage of infrastructures, casualties, condition about stranded vehicles and passengers, etc.; (3) Resource information, including relief supplies, evacuation spots, technical equipment, etc. The acquisition of the above information needs to make full use of traffic detection devices, geographic information system and other transport management equipment. In addition, close collaboration with other sectors is important in information acquisition and release.

Situation analysis is the next important step. Based on the information obtained, it is imperative to make a quick analysis of the situation with the assistance of intelligent transportation equipment about the following: (1) Road network capacity, as this can be considered as a reference point to start a certain pre-arranged emergency plan; (2) Traffic congestion state, as this determines whether to provide relief and response; (3) Relief requirements, as this involves the information that will be released, the measures taken and the instruments used.

Situation prediction is a further important step. The risk evolution under extreme weather events is a random and uncertain process. With the expansion and transmission of the impacts of some accidents, swift prediction about what will happen next and what actions should be prioritised are critical. It is important to foresee the following aspects: (1) Potential danger to people, as this will directly affect the subsequent rescue and evacuation arrangements; (2) Potential damage to society, as this will influence further resource allocation and warning release.

In brief, the activities in the management network level are to match the requirements in the operation network level. Such a matching process is affected by various complex factors, such as the reliability of information source, speed of response, uncertainty of environmental change, etc. Therefore, the matching process has strong levels of uncertainty, and this is reflected in two aspects: the first is that the matching process is a fuzzy process that may not be accurately measured; the second is that the matching process will give rise to some random incidents that may be difficult to be foreseen. So it is better to consider the matching character from fuzziness and randomness view.

The theory about fuzzy cognitive matching (Atanassov 1986) might provide a way to understand the essence of activities in the management network level and provide a means to describe the internal relationships between the dual networks under extreme weather events.

Let $U$ denote a given universe, and let $G$ denote a fuzzy cognitive subset in the universe $U$, that is:

$$
G=\left\{\left\langle x, \mu_{G}(x), \gamma_{G}(x)\right\rangle \mid x \in U\right\},
$$

where: $\mu_{G}(x): U \rightarrow[0,1]$ denotes membership function of $G ; \gamma_{G}(x): U \rightarrow[0,1]$ denotes non-membership function of $G$.

For any $x \in U$ that belongs to $G$, there is:

$$
0 \leq \mu_{G}(x)+\gamma_{G}(x) \leq 1 .
$$

If $U$ is a continuum, then:

$$
G={ }_{x} \int\left\langle\mu_{G}(x), \gamma_{G}(x)\right\rangle / x, \quad x \in U
$$


If $U$ is discrete, that is, $U=\left\{x_{1}, x_{2}, \cdots, x_{n}\right\}$, then:

$$
G=\sum_{i=1}^{n}\left\langle\mu_{G}(x), \gamma_{G}(x)\right\rangle / x_{i}, \quad x_{i} \in U, \quad i=1,2, \cdots, n .
$$

For any fuzzy cognitive subset of $U, \pi_{G}(x)=1-\mu_{G}(x)-\gamma_{G}(x)$ denotes the cognitive index of $x$ to $G$ and is a kind of estimation about the degree of uncertainty of $x$ to $G$.

For fuzzy cognitive matching, the expected precondition to adopt a series of emergency arrangements is denoted as $G$, and the actual phenomenon is denoted as $G^{\prime}$. Since $G^{\prime}$ cannot totally comply with $G$, an easy way to determine whether to adopt a series of emergency arrangements can be based on the comparison between $G^{\prime}$ and $G$. If the similarity is greater than a cognitive nearness $\lambda$, then transport managers can decided to start these emergency arrangements.

Cognitive nearness $\lambda$ expresses a kind of fuzzy similarity between two situations. If let $X$ and $Y$ denote fuzzy sets corresponding to two situations respectively, the cognitive nearness $\lambda(X, Y)$ can be defined as:

$$
N(X, Y)=\frac{1}{2}[X \cdot Y+(1-X \otimes Y)]
$$

where:

$$
\begin{aligned}
& X \bullet Y=\frac{1}{2}\left\{\underset{U}{\vee}\left[\mu_{X}(x) \wedge \mu_{Y}(x)\right]+\underset{U}{\vee}\left[\left(1-\gamma_{X}(x)\right) \wedge\left(1-\gamma_{Y}(x)\right)\right]\right\} ; \\
& X \otimes Y=\frac{1}{2}\left\{\hat{U}_{U}\left[\mu_{X}(x) \vee \mu_{Y}(x)\right]+\underset{U}{\widehat{N}}\left[\left(1-\gamma_{X}(x)\right) \vee\left(1-\gamma_{Y}(x)\right)\right]\right\} .
\end{aligned}
$$

Therefore: $\vee$ denotes taking the maximum; $\wedge$ denotes taking the minimum; $X \bullet Y$ denotes inner product; $X \otimes Y$ denotes outer product. When nearness is utilised to express matching degree, greater value of nearness implies better matching.

The formulation developed in this section reflects the essence of the matching control and may provide a kind of effective explanation about the digestion of the crisis induced by the snow event in early 2008.

\section{Quantitative evidence analysis}

Here, we try to provide a quantitative evidence to prove the above methodology from other objective approach by searching relevant news reports in Baidu, the largest Chinese search engine of the world. The Baidu news include news from the following types of sites: (1) the official publication of newspapers and magazines and the network version of official radios and televisions; (2) the official website of governments and relevant organizations; (3) the website portal, the local information harbour or the industrial information website that has a high-quality original news content or has a certain degree of user awareness with a faithful reading group in its target areas. Therefore, the news included in Baidu is convincing and influential and the news amount about an event can be seen as a proxy of the social concern and impact of the event. 
The keywords for the searching are Chinese words corresponding to "Guangzhou", "railway station", "passenger" and "stranded". We use the retrieval strategy "(Guangzhou) + (railway station $)+$ (passenger)" or "(Guangzhou $)+$ (railway station $)+($ stranded)". Baidu can list the resulting items in chronological order that provides an objective data source. Baidu can also automatically delete repeated news and classify reprinted news. Therefore, the resulting new items are all original. The temporal distribution of these news items serves as a proxy to disclose the evolutionary process and social impact variation of the crisis in the Guangzhou railway station under the snow event that provide quantitative evidence to prove the above methodology.

Since the snow event start on January 10, 2008, we choose a time span long enough to cover the evolutionary process of the crisis in the Guangzhou railway station. The time span is from January 10 to the end of March 2008. The news amount per day is listed in Table 1 and the corresponding data distribution is shown as Fig. 3.

Table 1. The news amount per day

\begin{tabular}{cccccccccccc}
\hline No. & Date & $\begin{array}{c}\text { News } \\
\text { amount }\end{array}$ & No. & Date & $\begin{array}{c}\text { News } \\
\text { amount }\end{array}$ & No. & Date & $\begin{array}{c}\text { News } \\
\text { amount }\end{array}$ & No. & Date & $\begin{array}{c}\text { News } \\
\text { amount }\end{array}$ \\
\hline 1 & Jan 10 & 14 & 22 & Jan 31 & 1000 & 43 & Feb 21 & 128 & 64 & Mar 13 & 8 \\
\hline 2 & Jan 11 & 41 & 23 & Feb 01 & 978 & 44 & Feb 22 & 54 & 65 & Mar 14 & 2 \\
\hline 3 & Jan 12 & 16 & 24 & Feb 02 & 1010 & 45 & Feb 23 & 42 & 66 & Mar 15 & 3 \\
\hline 4 & Jan 13 & 20 & 25 & Feb 03 & 848 & 46 & Feb 24 & 11 & 67 & Mar 16 & 6 \\
\hline 5 & Jan 14 & 95 & 26 & Feb 04 & 650 & 47 & Feb 25 & 90 & 68 & Mar 17 & 9 \\
\hline 6 & Jan 15 & 110 & 27 & Feb 05 & 427 & 48 & Feb 26 & 81 & 69 & Mar 18 & 5 \\
\hline 7 & Jan 16 & 98 & 28 & Feb 06 & 218 & 49 & Feb 27 & 36 & 70 & Mar 19 & 7 \\
\hline 8 & Jan 17 & 107 & 29 & Feb 07 & 140 & 50 & Feb 28 & 52 & 71 & Mar 20 & 4 \\
\hline 9 & Jan 18 & 101 & 30 & Feb 08 & 114 & 51 & Feb 29 & 54 & 72 & Mar 21 & 6 \\
\hline 10 & Jan 19 & 72 & 31 & Feb 09 & 112 & 52 & Mar 01 & 12 & 73 & Mar 22 & 1 \\
\hline 11 & Jan 20 & 88 & 32 & Feb 10 & 168 & 53 & Mar 02 & 18 & 74 & Mar 23 & 1 \\
\hline 12 & Jan 21 & 131 & 33 & Feb 11 & 180 & 54 & Mar 03 & 80 & 75 & Mar 24 & 3 \\
\hline 13 & Jan 22 & 151 & 34 & Feb 12 & 156 & 55 & Mar 04 & 44 & 76 & Mar 25 & 9 \\
\hline 14 & Jan 23 & 120 & 35 & Feb 13 & 230 & 56 & Mar 05 & 16 & 77 & Mar 26 & 13 \\
\hline 15 & Jan 24 & 148 & 36 & Feb 14 & 255 & 57 & Mar 06 & 56 & 78 & Mar 27 & 11 \\
\hline 16 & Jan 25 & 107 & 37 & Feb 15 & 149 & 58 & Mar 07 & 20 & 79 & Mar 28 & 13 \\
\hline 17 & Jan 26 & 157 & 38 & Feb 16 & 95 & 59 & Mar 08 & 6 & 80 & Mar 29 & 5 \\
\hline 18 & Jan 27 & 272 & 39 & Feb 17 & 80 & 60 & Mar 09 & 3 & 81 & Mar 30 & 2 \\
\hline 19 & Jan 28 & 796 & 40 & Feb 18 & 155 & 61 & Mar 10 & 14 & 82 & Mar 31 & 2 \\
\hline 20 & Jan 29 & 1020 & 41 & Feb 19 & 151 & 62 & Mar 11 & 18 & & & \\
\hline 21 & Jan 30 & 1040 & 42 & Feb 20 & 107 & 63 & Mar 12 & 16 & & & \\
\hline & & & & & & & & & & & \\
\hline
\end{tabular}

From Table 1 and Fig. 3, we can see that although the now started on January 10 and official news media have sensed the deteriorating situation of the operation level in the Guangzhou railway station, the emergency response from the management level was not enough so that the "golden time" of half a month to save the situation was lost. Ultimately, the crisis in the Guangzhou railway station burst out and we can see this on Fig. 3 highlighted by sharply increased 


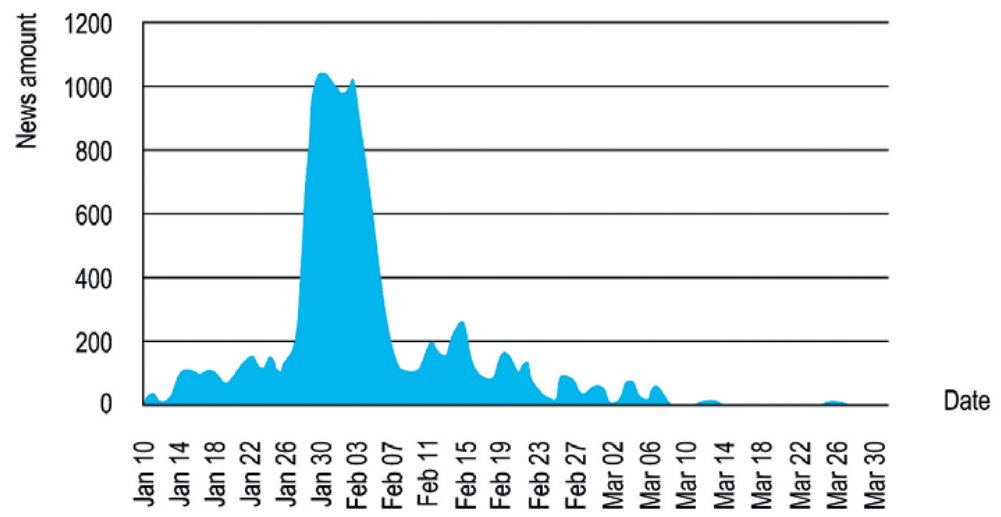

Fig 3. The distribution of the data

relevant news reports, which represent the severity of the situation, extensive social attention, huge social impact and surged information provision. Under the pressure from various aspects, the actors in the management level have to act collaboratively to adopt matching control to cope with the crisis. By Feb 05, the situation got control, which is represented in Table 1 and Fig. 3, that is, the relevant news amount fell below 400 per day and did not rebound any more. However, the social impression and impact of the crisis sustained for quite a time, which is represented by uninterrupted relevant news reports in the subsequent one month.

The quantitative evidence highlights the social impact of the disorder in the operation level and the delayed matching control from the operation level. It further strengthened the viewpoint that the activities in the management network level should match the requirements in the operation network level under extreme weather events.

\section{Discussion}

The now event in South China in Early 2008 as a example confirmed the theoretical dual-network structure of transport system under extreme weather, and highlighted the importance of anticipation and collaboration in achieving effective matching control.

Extreme weather events may not only impact on the physical components of transport system but it may also induce social and psychological strain. Therefore, transport management under extreme weather risks should pay attention to not only physical aspects but also psychological and behaviour aspects of the situation. The task of transport managers as well as other critical infrastructure managers and local governors is to swiftly build firewalls for physical systems and social systems to block the impact evolution path of extreme weather. Here, the firewall refers to risk reduction strategies, which include strategies related to key preparatory measures for the physical systems to withstand extreme events if the engineering is deficient, strategies related to the forecasting and warnings systems and strategies related to the information management processes. 
To identify the impact evolution path of extreme weather event swiftly and make prompt response to built proper firewalls, it needs not only some critical resources but it also needs incentive compatibility mechanism (Miao et al. 2010) to guarantee the smooth implementation of relevant tasks.

Preparedness and response to extreme weather events need a mass of information and resource, both of which require extensive collaboration between the different sectors. An active transport sector would anticipate the risks and send early warning messages to the operation network. Active anticipatory action can reduce the economic and life loss. A preferable system for transport management under extreme weather risks would be to: (1) distinguish the risks from potential extreme weather events and inform the operation network; (2) capture important information from the operation level and make swift response after extensive collaboration. In contrast, a passive transport management waits for accidents to happen and then makes a limited response.

The snow event also highlighted the importance of effective information provision in guiding travellers' psychology and behavioural responses. Uncertainty needs to be reduced through information provision to help travellers improve their self-adjustment capability, and this is an important topic for intelligent transportation system research. For example, information dissemination channels are commonly used with radio, television, internet and other public media (Khattak, DePalma 1997). To ensure the accuracy and authority, local government needs to be involved in the construction and management of a dynamic information release system that covers wireless communication technology, transport geographic information system, database technology, and other devices (Zavadskas 2008). These need to be combined in a systematic way to reduce the loss caused by extreme weather events, and to direct daily traffic and enhance efficiency.

\section{Conclusions}

Extreme weather events are difficult for the transport sector to cope with, as it is often the transport system itself that is disrupted. However, that same transport system is needed to provide the means by which emergency workers and supplies can get to the affected area. Anticipation and early warning, together with sufficient preparedness and swift response are all critical components in providing the means to reduce the impacts of extreme weather events. However, all these elements require close collaboration between the various sectors, each of which might be affiliated to different regions or different administrative organisations. Such social-techno system exhibits complexity in the dual-network. The operation network may present collective behaviour and induce new challenges for transport management. The effectiveness of emergency response lies in the matching of the activities in the management network with the requirements of operation network. Information transmission plays a critical role in such matching process. Evidence from the case study on the snow event in South China in early 2008 partly supports the theoretical formulation given in this paper. However, other aspects need further research. These include the types and forms of information to be provided, clear leadership and coordination between the different agencies involved in 
responding to events, more consideration being given to anticipatory as well as responsive actions, and further exploration as to the means by which the public can be better engaged in playing an active role in event response. Although this paper focuses on transport system, the viewpoint and finding have potential broad significance to system of systems engineering (Bristow et al. 2012), which call for a dual-network perspective and system thinking for governance. To extend this basic research, relevant policy, legislation, strategies, approaches or methods that have practical implication might be good aspects for further research, which may contribute to not only risk and emergency management but also sustainable development of economy and society.

\section{Acknowledgements}

The authors acknowledge the support from the National Natural Science Foundation of China (Grant No. 71101036, Grant No. 61074133, Grant No. 71390522), the Fundamental Research Funds for the Central Universities (Grant No. HIT.BRETIII.201208), the Research Fund for the Doctoral Program of Higher Education (Grant No. 20112302120037), and the Natural Science Foundation of Heilongjiang Province (Grant No. G201014).

\section{References}

Al-Deek, H.; Emam, E. B. 2006. New methodology for estimating reliability in transportation networks with degraded link capacities, Journal of Intelligent Transportation Systems 10(3): 117-129. http://dx.doi.org/10.1080/15472450600793586

Atanassov, K. T. 1986. Intuitionistic fuzzy sets, Fuzzy Sets and Systems 20(1): 87-96. http://dx.doi.org/10.1016/S0165-0114(86)80034-3

Banerjee, A. V. 1992. A simple model of herd behavior, Quarterly Journal of Economics 107(3): 797-817. http://dx.doi.org/10.2307/2118364

Bikhchandani, S.; Hirshleifer, D.; Welch, I. A. 1992. A theory of fads, fashion, custom and cultural change as informational cascades, Journal of Political Economy 100(5): 992-1027. http://dx.doi.org/10.1086/261849

Bosher, L.; Carrillo, P.; Dainty, A.; Glass, J.; Price1, A. 2007. Realising a resilient and sustainable built environment: towards a strategic agenda for the United Kingdom, Disasters 31(3): 236-255. http://dx.doi.org/10.1111/j.1467-7717.2007.01007.x

Bristow, M.; Fang, L.; Hipel, K. W. 2012. System of systems engineering and risk management of extreme events: concepts and case study, Risk Analysis 32(11): 1935-1955. http://dx.doi.org/10.1111/j.1539-6924.2012.01867.x

Eusgeld, I.; Nan, C.; Dietz, S. 2011. "System-of-systems" approach for interdependent critical infrastructures, Reliability Engineering \& System Safety 96(6): 679-686. http://dx.doi.org/10.1016/j.ress.2010.12.010

Helbing, D.; Farkas, I.; Vicsek, T. 2000. Simulating dynamical features of escape panic, Nature 407(6803): 487-490. http://dx.doi.org/10.1038/35035023

Hey, J. D.; Morone, A. 2004. Do markets drive out lemmings - or vice versa?, Economica 71(284): 637-659. http://dx.doi.org/10.1111/j.0013-0427.2004.00392.x 
Holland, J. H. 1995. Hidden order: how adaptation build complexity. Addison-Wesley Publishing Company. $185 \mathrm{p}$.

Hongler, M. O.; Gallay, O.; Huelsmann, M.; Cordes, P.; Colmorn, R. 2010. Centralized versus decentralized control - a solvable stylized model in transportation, Physica A-Statistical Mechanics and Its Applications 389(19): 4162-4171. http://dx.doi.org/10.1016/j.physa.2010.05.047

IPCC. 2001. Intergovernmental Panel on Climate Change. IPCC Third Assessment Report - Climate Change 2001. $83 \mathrm{p}$.

IPCC. 2007. Climate Change 2007: Impact, adaptation and vulnerability, in Parry, M. L.; Canziani, O. F.; Palutikof, J. P.; van der Linden, P. J.; Hanson. C. E. (Eds.). Contribution of Working Group II to the Fourth Assessment Report of the Intergovernmental Pane on Climate Change. Cambridge: Cambridge University Press. 976 p.

IPCC. 2012. Managing the risks of extreme events and disasters to advance climate change adaptation, in Field, C. B.; Barros, V.; Stocker, T. F.; Qin, D.; Dokken, D. J.; Ebi, K. L.; Mastrandrea, M. D.; Mach, K. J.; Plattner, G.-K.; Allen, S. K.; Tignor, M.; Midgley, P. M. (Eds.). A Special Report of Working Groups I and II of the Intergovernmental Panel on Climate Change. Cambridge and New York: Cambridge University Press. 582 p.

Jenelius, E. 2009. Network structure and travel patterns: explaining the geographical disparities of road network vulnerability, Journal of Transport Geography 17(3): 234-244. http://dx.doi.org/10.1016/j.jtrangeo.2008.06.002

Johansson, J.; Hassel, H. 2010. An approach for modelling interdependent infrastructures in the context of vulnerability analysis, Reliability Engineering \& System Safety 95(12): 1335-1344. http://dx.doi.org/10.1016/j.ress.2010.06.010

Keating, J. P. 1982. The myth of panic, Fire Journal 76(3): 57-61.

Kelley, H. H.; Condry, J. C. Jr.; Dahlke, A. E.; Hill, A. H. 1965. Collective behavior in a simulated panic situation, Journal of Experimental Social Psychology (1): 20-54. http://dx.doi.org/10.1016/0022-1031(65)90035-1

Khattak, A. J.; DePalma, A. 1997. The impact of adverse weather conditions on the propensity to change travel decisions: a survey of Brussels commuters, Transportation Research Part A-Policy and Practice 31(3): 181-203. http://dx.doi.org/10.1016/S0965-8564(96)00025-0

Kovats, R. S.; Campbell-Lendrum, D.; Matthies, F. 2005. Climate change and human health: estimating avoidable deaths and disease, Risk Analysis 25(6): 1409-1418. http://dx.doi.org/10.1111/j.1539-6924.2005.00688.x

Low, D. J. 2000. Statistical physics - following the crowd, Nature 407(6803): 465-466. http://dx.doi.org/10.1038/35035192

Lux, T. 1995. Herd behavior, bubbles and crashes, The Economic Journal 105(431): 881-896. http://dx.doi.org/10.2307/2235156

Miao, X.; Yu, B.; Xi, B.; Tang, Y. H. 2010. Modeling of bilevel games and incentives for sustainable critical infrastructure system, Technological and Economic Development of Economy 16(3): 365-379. http://dx.doi.org/10.3846/tede.2010.23

Miao, X.; Yu, B.; Xi, B.; Tang, Y. H. 2011. Risk and regulation of emerging price volatility of non-staple agricultural commodity in China, African Journal of Agricultural Research 6(5): 1251-1256.

Mirza, M. M. Q. 2003. Climate change and extreme weather events: can developing countries adapt?, Climate Policy 3(3): 233-248. http://dx.doi.org/10.3763/cpol.2003.0330

Nagurney, A.; Qiang, Q.; Nagurney, L. S. 2010. Environmental impact assessment of transportation networks with degradable links in an era of climate change, International Journal of Sustainable Transportation 4(3): 154-171. http://dx.doi.org/10.1080/15568310802627328 
Peralta, E. 2011. Breaks record for most billion-dollar weather disasters. National News [online], [cited 17 February 2012]. Available from Internet: http://www.npr.org/blogs/thetwo-way/2011/12/07/143304115/2011breaks-record-for-most-billion-dollar-weather-disasters? $\mathrm{ft}=1 \& \mathrm{f}=1001$

Quarantelli, E. 1957. The behavior of panic participants, Sociology and Social Research (41): 187-194.

Santella, N.; Steinberg, L. J.; Parks, K. 2009. Decision making for extreme events: modeling critical infrastructure interdependencies to aid mitigation and response planning, Review of Policy Research 26(4): 409-422. http://dx.doi.org/10.1111/j.1541-1338.2009.00392.x

Shi, P. J.; Liu, J.; Yao, Q. H.; Tang, D.; Yang, X. 2007. Integrated disaster risk management of China, in Session III: Financial Management: Role of Insurance Industry, Financial Markets, and Governments. Part B: Developing Country Perspective, 26-27 February, 2007, Hyderabad, India. 23 p.

Shi, X. H.; Xu, X. D.; Lu, C. G. 2010. The dynamic and thermodynamic structures associated with a series of heavy precipitation events over China during January 2008, Weather and Forecasting 25(4): 1124-1141. http://dx.doi.org/10.1175/2010WAF2222335.1

Suarez, P.; Anderson, W.; Mahal, V.; Lakshmanan, T. R. 2005. Impacts of flooding and climate change on urban transportation: a systemwide performance assessment of the Boston Metro Area, Transportation Research Part D-Transport and Environment 10(3): 231-244. http://dx.doi.org/10.1016/j.trd.2005.04.007

Sumalee, A.; Uchida, K.; Lam, W. H. K. 2011. Stochastic multi-modal transport network under demand uncertainties and adverse weather condition, Transportation Research Part C-Emerging Technologies 19(2): 338-350. http://dx.doi.org/10.1016/j.trc.2010.05.018

Wardrop, J. G. 1952. Some theoretical aspects of road traffic research, in Proceedings of the Institute of Civil Engineers, Part II, Vol. 1: 325-378.

Xinhua News Agency. 2008. Death toll, traffic chaos worsen with more snow, sleet in China [online], [cited 21 July 2011]. Available from Internet: http://news.xinhuanet.com/english/2008-01/27/ content_7507926.htm

Zavadskas, E. K. 2008. Design and application of intelligent information systems, Book Reviews, Journal of Business Economics and Management 9(3): 235-236. http://dx.doi.org/10.3846/1611-1699.2008.9.235-236

Zhu, Y.; Thot, Z. 2001. Extreme weather events and their probabilistic prediction by the NCEP ensemble forecast system, Preprints of the Symposium on Precipitation Extremes: Prediction, Impacts, and Responses, 14-19 January 2001, Albuquerque.

Zio, E.; Sansavini, G. 2011. Modeling interdependent network systems for identifying cascade-safe operating margins, IEEE Transactions on Reliability 60(1): 94-101.

http://dx.doi.org/10.1109/TR.2010.2104211

Xin MIAO. Doctor, Associate Professor in the School of Management at Harbin Institute of Technology, the author of more than 30 research papers. He has been a Postdoctoral Researcher and Visiting Research Associate at Transport Studies Unit, School of Geography and the Environment, University of Oxford, United Kingdom. He runs a number of research projects and serves as peer reviewer for several international refereed journals. Research interests include systems engineering, infrastructure management, emergency management, transport management, environmental management and sustainable development.

David BANISTER. Doctor, Professor of Transport Studies, Director of the Transport Studies Unit, School of Geography and the Environment (SoGE), University of Oxford, United Kingdom. During 2009-2010 he was also Acting Director of the Environmental Change Institute in SoGE. He has authored and edited 19 books that summarise his own research and some of the international projects that he has been involved with. He has also authored (or coauthored) more than 150 papers in international refereed 
journals, together with a similar number of other papers in journals or as contributions to books. Other outputs include research monographs (over 50), and reports for research sponsors (over 100). His current research has concentrated on five main areas: (1) policy scenario building; (2) reducing the need to travel; (3) climate change, energy and environmental modelling; (4) transport investment and economic development; (5) rural transport and employment.

Yanhong TANG. PhD student at the Department of Public Management in the School of Management, Harbin Institute of Technology. Research interests include water pollution regulation, risk management and emergency management.

Min LI. Postgraduate at the Department of Public Management in the School of Management, Harbin Institute of Technology. Research interests include risk management and emergency management.

Bao XI. Doctor, Professor of School of Public Administration, Dalian University of Technology. He published more than 100 research papers. Research interests include infrastructure management, risk management and emergency management. 